\title{
Mutation Screening Using Automated Bidirectional Dideoxy Fingerprinting
}

BioTechniques 28:134-138 (January 1999)

\author{
Yuriy O. Shevchenko, Sherri \\ J. Bale and John G. Compton \\ National Institute of Arthritis, \\ Musculoskeletal and Skin \\ Diseases, National Institutes of \\ Health, Bethesda, MD, USA
}

\section{INTRODUCTION}

As researchers identify gene defects in human diseases, there are increasing expectations from patients that mutation detection for diagnosis and genetic counseling will be made available to the medical community. Mutation testing represents a real opportunity for families with genetic disease to achieve better control of their own destinies. In disease genes in which the defects may be due to one or only a few specific mutations, sequence-specific tests have been developed using, for example, allelespecific amplification, restriction enzyme digestion or other advanced techniques such as ligase chain reaction and biochips. For other diseases that arise from a mutation that could occur anywhere within a gene, screening of the entire gene is required. Sequencing, while virtually $100 \%$ effective at finding mutations, remains technically challenging, resource and labor-intensive and is generally the least cost-effective screening technique to perform. Alternative mutation screening methods that are efficient, rapid, high-throughput and automated, are better suited to the needs of clinical laboratories where time is critical and high sensitivity is crucial.

Single-stranded conformational polymorphism analysis (SSCP) is one of the most common methods used for mutation screening (5). It is based on detecting changes in the electrophoretic mobility of partially re-annealed DNA fragments caused by sequence variation. Despite improvements, SSCP remains only $60 \%-90 \%$ efficient at uncovering mutations (8) and is achievable only for short DNA fragments ( $200 \mathrm{bp}$ ). The method requires that electrophoresis conditions be optimized for each unique fragment and that they need to be performed at a low temperature (such as $4^{\circ} \mathrm{C}$ ).

Heteroduplex analysis is another screening approach that detects mobility changes between re-annealed complementary and mismatched doublestranded PCR fragments (10). It is less efficient than SSCP and has a similar range of problems with its implementation. The combination of SSCP and heteroduplex analysis has improved mutation detection but still did not reach $100 \%$ efficiency (9).

The most effective screening technique available may be dideoxy fingerprinting (ddF; see Reference 8), which combines dideoxynucleotide sequencing with SSCP analysis. In ddF, fragments generated by a single dideoxy sequencing reaction (i.e., ddGTP) with 32P-labeled primers are resolved on an SSCP-type gel. Changes in the banding pattern from sequence variations are readily detected by an inspection of control and test samples run side by side. This method has been found to detect $100 \%$ of mutations when both strands of the target sequence are evaluated (8).

An important improvement was the introduction of a bidirectional dideoxy fingerprint $(\mathrm{Bi}-\mathrm{ddF})$ protocol, in which both strands are examined simultane- 
Table 1. Sequence Variations in Exon 5 of $P$ TCH Corresponding to Altered Bi-ddF Patterns

\begin{tabular}{|c|c|c|c|}
\hline \multirow[b]{2}{*}{ Sample } & \multirow[b]{2}{*}{ Status } & \multicolumn{2}{|c|}{ Sequence Variations } \\
\hline & & Gene & Protein \\
\hline 9 & NBCC & $\mathrm{ACA} \rightarrow \mathrm{ACG}$ & $\mathrm{Thr} \rightarrow \mathrm{Thr}$ \\
\hline 12 & NBCC & $\mathrm{ACA} \rightarrow \mathrm{ACG}$ & $\mathrm{Thr} \rightarrow \mathrm{Thr}$ \\
\hline 15 & NBCC & $\mathrm{TTA} \rightarrow \mathrm{TG} A$ & Leu $\rightarrow$ Term \\
\hline \multirow[t]{2}{*}{19} & NBCC & $\underline{\mathrm{GT}} \rightarrow \underline{\mathrm{TT}}$ & frameshift/truncation \\
\hline & & $\mathrm{ACA} \rightarrow \mathrm{ACG}$ & $\mathrm{Thr} \rightarrow \mathrm{Thr}$ \\
\hline 20 & NBCC & $\mathrm{TA} \underline{\mathrm{C}} \rightarrow \mathrm{TA} \underline{\mathrm{A}}$ & Tyr $\rightarrow$ Term \\
\hline control & control & $\mathrm{ACA} \rightarrow \mathrm{ACG}$ & $\mathrm{Thr} \rightarrow \mathrm{Thr}$ \\
\hline
\end{tabular}

ously (3). Both strands of 400 bp fragments can be analyzed in a single lane or 600 bp may be evaluated, albeit without overlapping, at a lower efficiency of detection. However, successful Bi-ddF has several less desirable features including the requirement for band patterns of equal intensity from both strands and the desirability of running gels at lower temperature, usually in a cold room. Additionally, $\mathrm{Bi}$-ddF data is generated by autoradiography, a time-consuming and inconvenient process. Recently, RNA-based $\mathrm{ddF}$ analysis using an automated DNA sequencer was described (4).

Recognizing the power of $\mathrm{Bi}-\mathrm{ddF}$ for mutation screening, we developed a rapid nonradioactive $\mathrm{Bi}$-ddF mutation analysis system that is suited to a clinical environment and that can be performed on the bench top rather than in a cold room. Our procedure is standardized, uses an automated DNA analyzer and is therefore easy to perform and scale up for multiple samples.

One of its advantages is to greatly simplify mutation verification by sequencing. Using primers labeled with two different fluorescent dyes and the dual-dye DNA Analyzer 4200 (LICOR, Lincoln, NE, USA), our procedure allows simultaneous collection of separate images for reverse and forward directions, thus simplifying the band patterns and their analysis. Because image collection is automated and data is stored in digital format, more power and flexibility in data analysis is possible. Here, we demonstrate automated $\mathrm{Bi}-\mathrm{ddF}$ for mutation screening of a DNA fragment encompassing exon 5 of Patched $(P T C H)$ in a panel of 22 patients. Mutations in
PTCH are responsible for nevoid basal cell carcinoma (NBCC; Gorlin Syndrome), an autosomal dominant genetic disorder with an estimated prevalence as high as 1 in 57000 (1).

\section{MATERIALS AND METHODS}

\section{Sample Preparation}

DNA for analysis was prepared from buccal swabs collected from consenting patients and processed as in Reference 6. Two microliters of each sample were used as template in each PCR assay.

\section{Primer Design and Synthesis}

Sequence-specific $P T C H$ primers to amplify exon 5 (forward, 5'-GCAAAAATTTCTCAGGAACACC-3' and reverse, 5'-TGGAACAAACAATGATAAGCAA-3') were designed based on published sequences (2). The sequences M13F (5'-CACGACGTTGTAAAACGAC-3') and M13R (5'-GGATAACAATTTCACACAGG-3') were added to the $5^{\prime}$ ends of reverse and forward primers, respectively.

\section{DNA Amplification}

DNA fragments were amplified (DNA Engine; MJ Research, Watertown, MA, USA) using $2 \mu \mathrm{L}$ of buccal sample in $25 \mu \mathrm{L}$ volume, $1.25 \mathrm{U}$ of RedTaq DNA polymerase (Sigma, St. Louis, MO, USA) and 10 pmol of each primer. The temperature profile was $94^{\circ} \mathrm{C}$ for $2 \mathrm{~min}, 35$ cycles of $94^{\circ} \mathrm{C}$ for $15 \mathrm{~s}, 60^{\circ} \mathrm{C}$ for $30 \mathrm{~s}, 72^{\circ} \mathrm{C}$ for $1 \mathrm{~min}$ and storage at $4^{\circ} \mathrm{C}$.

\section{Purification of DNA Fragments}

PCRs were loaded on a $2 \%$ agarose gel (SeaKem ${ }^{\circledR}$ LE; FMC BioProducts, Rockland, ME, USA) in $1 \times$ TAE buffer (40 mM Tris-acetate, $1 \mathrm{mM}$ EDTA). Fragments of the expected length were cut out, purified using the Ultra Clean GelSpin purification kit (Mo Bio Laboratories, Solana Beach, CA, USA) according to the manufacturer's protocol and recovered in $50 \mu \mathrm{L}$ elution volume.

\section{Bidirectional Dideoxy Fingerprinting}

Bi-ddF reactions. Sequencing reactions used ddGTP and contained $2 \mu \mathrm{L}$ of $\mathrm{G}$ termination mixture, $0.25 \mu \mathrm{L}$ of Taq DNA polymerase from Sequitherm Excel $^{\mathrm{TM}}$ II Sequencing Kit (Epicentre, Madison, WI, USA), along with $2 \mu \mathrm{L}$ (25-100 ng) of purified PCR fragment and $0.25 \mu \mathrm{L}(0.25 \mathrm{pmol})$ of $\mathrm{M} 13 \mathrm{~F}$ IRD700 and of M13R IRD800 fluorescent dye labeled primers (LI-COR). Cycle sequencing was performed on the DNA Engine using the following temperature profile: $94^{\circ} \mathrm{C}$ for $2 \mathrm{~min}$, then $94^{\circ} \mathrm{C}$ for $30 \mathrm{~s}, 58^{\circ} \mathrm{C}$ for $15 \mathrm{~s}, 72^{\circ} \mathrm{C}$ for $15 \mathrm{~s}$ repeated for 30 cycles. Ten microliters of stop solution (LI-COR) were added to the reactions.

\section{Polyacrylamide Gel Preparation and Analysis}

A dual-dye DNA analyzer 4200 with a custom cooling jacket accessory attached to the gel plate assembly was used for Bi-ddF electrophoresis and data collection available from LI-COR. A polyacrylamide gel consisting of $0.5 \times$ MDETM $^{\mathrm{TM}}$ (FMC BioProducts) with $10 \%$ glycerol in $0.6 \times$ Tris-taurine buffer (TTE, glycerol-tolerant gel buffer; USB, Cleveland, OH, USA) was cast in $25 \mathrm{~cm}$ gel plates with 0.25 $\mathrm{mm}$ spacers and a 48-well rectangular comb (LI-COR). TTE at $1 \times$ contains $10.8 \mathrm{~g}$ of Tris, $3.6 \mathrm{~g}$ of taurine and $0.2 \mathrm{~g}$ of EDTA per liter.

After gel polymerization, the cooling accessory was attached to the front plate of the apparatus. The plate/jacket assembly was mounted on the DNA analyzer and connected to a MultiTemp ${ }^{\mathrm{TM}}$ II circulating water bath (Amersham Pharmacia Biotech, Piscataway, NJ, 


\section{Research Report}

USA) set at $5^{\circ} \mathrm{C}$. After temperature equilibration, the samples were denatured for $3 \mathrm{~min}$ at $95^{\circ} \mathrm{C}$, cooled on ice, loaded $(1 \mu \mathrm{L})$ on the gel and electrophoresed in 0.6× TTE for $8 \mathrm{~h}$. The electrophoresis run profile that was typically used for DNA sequencing for a $25 \mathrm{~cm}$ gel was modified by switching off gel heating and setting the power to $8 \mathrm{~W}$.

Image analysis. Images of the collected data were analyzed by visual comparison of sample and control lanes using the Image Manipulation utility from Base ImagIR software package (LI-COR).

\section{Sequencing}

Cycle sequencing of the PCR fragment template was performed with the Sequitherm Excel II sequencing kit using the near infrared fluorescent-tagged primers M13F IRD700 and M13R IRD800 according to the manufacturer's protocols and with the amplification profile for Bi-ddF reactions already described. Sequencing reactions were analyzed on the dual-dye DNA analyzer 4200 on $41 \mathrm{~cm}, 6 \%$ Long Ranger ${ }^{\mathrm{TM}}$ denaturing polyacrylamide gels (FMC BioProducts) using standard DNA ana- lyzer 4200 running parameters. Sequences were generated from the data images using Base ImagIR LI-COR software and were further analyzed with Sequencher software (GeneCodes, Ann Arbor, MI, USA).

\section{RESULTS AND DISCUSSION \\ Efficiency and Reproducibility of the Method}

To demonstrate automated Bi-ddF, we screened a 242 bp DNA fragment
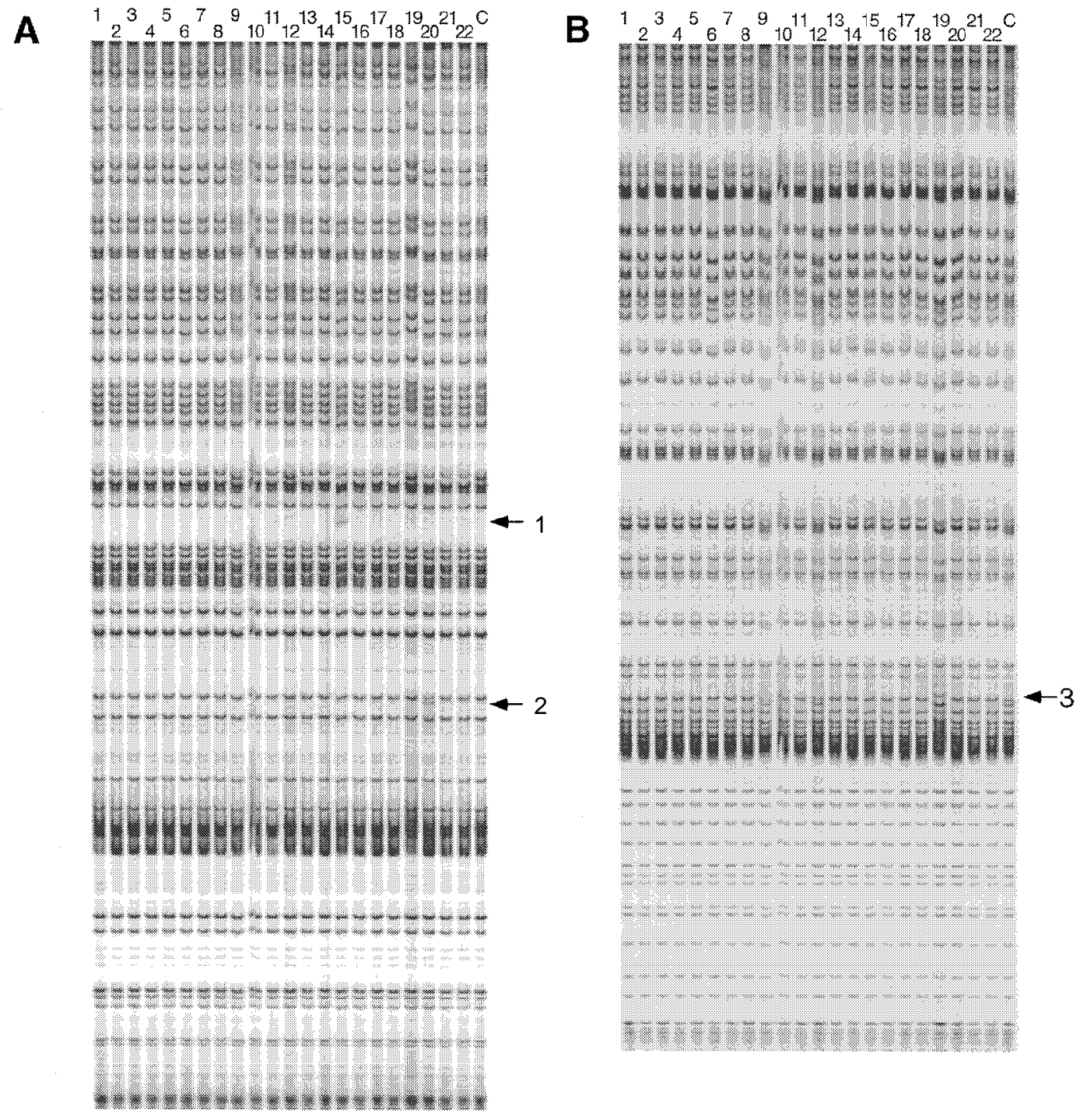

Figure 1. Bi-ddF profiles of $P T C H$ exon 5 in a panel of 23 individuals. (A) Image generated from the coding strand. (B) Image generated from the noncoding strand. Lanes 1-22, patients; lane C, control sample. Arrows indicate alterations in Bi-ddF pattern (see text). 
(PTCH exon 5) in a panel of 22 patients along with a control sample. Variations were observed in the $\mathrm{Bi}-\mathrm{ddF}$ profiles in 6 samples (Figure 1). These profiles varied from the simple presence of an extra band (Figure 1A, lane 15) to shifts in all bands larger than a particular fragment size (Figure 1B, lanes 6, 12 and 19). Some changes could only be detected on one of the strands, thus validating the need for bidirectional analysis. Both types of changes observed were in agreement with previous works (3). We sequenced all 23 templates in both directions to confirm that the observed $\mathrm{Bi}$-ddF variations were from differences in DNA sequence and also to verify the absence of variations in other samples. Table 1 presents a summary of the analysis.

All changes in $\mathrm{Bi}-\mathrm{ddF}$ profiles proved to be due to single nucleotide sequence variations in the corresponding DNA fragments. The extra band in lane 15 (Figure 1A, arrow 1) corresponded to the presence of $\mathrm{G}$ and $\mathrm{T}$ on the coding strand and was detected by the ddGTP-sequencing component of Bi$\mathrm{ddF}$. In contrast, the extra band in lane 20 (Figure 1A, arrow 2) was associated with a change from $\mathrm{C}$ to $\mathrm{A}$ in the coding strand, which apparently altered the mobility of the fragment. Shifts in mobility in many bands in lanes 9, 12, 19 and $\mathrm{C}$ (Figure 1B) corresponded to the substitution of $\mathrm{G}$ for $\mathrm{A}$ on the coding strand and $\mathrm{C}$ for $\mathrm{T}$ on the noncoding strand. The Bi-ddF patterns of the sample in lane 19 were also affected by a second sequence variation, $\mathrm{C}$ to $\mathrm{A}$ for the noncoding strand (a unique band is indicated on Figure 1B, arrow 3). Lanes 9, 12 and $\mathrm{C}$ produced identical patterns on Bi-ddF, and bidirectional sequencing proved that these samples possessed identical sequence. The Bi-ddF profiles that contained no changes were identical on sequencing, as expected.

Several of the observed sequence variations represent true heterozygous mutations in the PTCH gene (Table 1). In two patients, the nucleotide substitution alters the amino acid codon to a stop codon (Figure 1A, samples 15 and 20), predicting premature termination of translation and truncation of the protein. Another sample (Figure 1B, sample 19) reveals modification of the splice site donor sequence, which re- sults in aberrant mRNA splicing. Silent, third-position codon changes representing non-disease-associated polymorphisms were found in other patients (Figure 1, samples 12, 19 and C). Overall, the method identified all the sequence variations in the templates analyzed, and identical band patterns were observed for templates with identical sequence composition.

These data, along with similar results from many other templates, were obtained without any optimization procedures. Thus, our method allows variations in sequence to be distinguished by a simple examination of the Bi-ddF pattern, identifying specific fragments for sequencing and providing a basis for high-throughput $\mathrm{Bi}-\mathrm{ddF}$ mutation analysis.

\section{Standardized Primers}

We have adopted the use of composite PCR primers to achieve high-quality, reproducible $\mathrm{Bi}-\mathrm{ddF}$ and sequencing data with the dual-dye DNA analyzer. Composite primers consist of gene-specific sequences tailed at the $5^{\prime}$ end with either M13F or M13R. With these primers, the amplified fragments were each flanked with sequences of M13F and M13R, and all analyses were performed with only two labeled primers (M13F IRD700 and M13R IRD800) using the same cycling parameters for all $\mathrm{Bi}-\mathrm{ddF}$ and follow-up sequencing reactions. This approach becomes even more convenient for large genes. For example, the $P T C H$ gene consists of 24 exons. We note that the results described here for exon 5 of $P T C H$ were obtained with no special optimization, as was data from many other fragments we have analyzed (not shown). This procedure simplifies large-scale screening of samples, and facilitates automation. Use of the automated DNA analyzer allowed us to display the Bi-ddF profiles over a wide range of intensities, which circumvented the problem of differential intensities across samples due to unequal template DNA concentration.

\section{Bi-ddF Gel Running Conditions}

We have tested a number of combinations of gel matrices, additives, buffers and electrophoretic conditions. 
Bi-ddF has been observed to be most sensitive between $14^{\circ} \mathrm{C}$ and $20^{\circ} \mathrm{C}$. At room temperature, $\mathrm{Bi}$-ddF on the DNA analyzer ran at approximately $40^{\circ} \mathrm{C}$ at 8 W during electrophoresis. We used a cooling accessory to lower the gel temperature measured at the thermoplate of the DNA analyzer to $17^{\circ} \mathrm{C}$. The addition of $10 \%$ glycerol to $0.5 \times$ MDE gel greatly improved resolution. The automated system enabled us to work readily with glycerol-containing gels, because the post-electrophoreric processing necessary in manual analysis was eliminated. Our buffer tests showed that use of 0.6× TTE buffer resulted in sharper images as compared to TBE buffer and therefore improved visual analysis (data not shown).

\section{Advantages of the Bidirectional Protocol}

The use of the dual-dye DNA analyzer allowed us to generate separate images that corresponded to the coding and noncoding strands in the Bi-ddF analysis. This approach has several advantages due to the reduced number of bands in the patterns. One is that the $\mathrm{Bi}$-ddF patterns are analyzable and can be readily compared among different samples over sequences of at least 500 bp. Another advantage is the elimination of any optimization step sometimes required to equalize band intensities for the sequences generated from the two primers. In addition, the location of a suspect sequence variation in a DNA fragment is less ambiguous. For the cases in which band pattern variations were observed, identification of changes by sequencing could easily be performed in both directions (7) using the ddF primers in a standard cycle sequencing protocol.

In summary, we have developed a rapid automated method for mutation discovery that can be performed in a research or clinical laboratory setting. Though we used a modified dual-wavelength DNA analyzer for this purpose, it is likely that other DNA analyzers could be readily used with similar modifications (an external cooling assembly and substituting analyzer-specific dyelabeled primers). We have used our procedure to screen 25 DNA fragments that incorporate all the exons of the
$P T C H$ gene in 22 patients and present data here from one exon as an example. We believe that automated fluorescent Bi-ddF screening can be used successfully in many diagnostic situations to provide high-efficiency mutation detection for a variety of genetic disorders, particularly those in which the gene is large and mutations are found to occur throughout the gene.

\section{ACKNOWLEDGMENTS}

We would like to thank the LI-COR team, and especially Dr. H. Osterman, R. Bromley and R. Bruce for collaboration and friendly support.

\section{REFERENCES}

1.Farndon, P.A., R.G. Del Mastro, D.G.R. Evans and M.W. Kilpatrick. 1992. Location of gene for Gorlin syndrome. Lancet 339:581582.

2.Hahn, H., C. Wicking, P.G. Zaphiropoulous, M.R. Gailani, S. Shanley, A. Chidambaram, I. Vorechovsky, E. Holmberg et al. 1996. Mutations of the human homolog of Drosophila patched in the nevoid basal cell carcinoma syndrome. Cell 85:841-851.

3.Liu, Q., J. Feng and S.S. Sommer. 1996. Bidirectional dideoxy fingerprinting (Bi-ddF): a rapid method for quantitative detection of mutations in genomic regions of 300-600 bp. Hum. Mol. Genet. 5:107-114.

4.Martincic, D., M.J. Koury, K. Gale and J.A. Whitlock. 1999. Detection of mutations by automated fluorescence/RNA-based dideoxy fingerprinting. Oncogene 18:617-621.

5.Orita, M., H. Iwahana, H. Kanazawa, K. Hayashi and T. Sekiya. 1989. Detection of polymorphisms of human DNA by gel electrophoresis as single-strand conformation polymorphisms. Proc. Natl. Acad. Sci. USA 86:2766-2770.

6.Richards, B., J. Skoletsky, A.P. Shuber, R. Balfour, R.C. Stern, H.L. Dorkin, R.B. Parad, D. Witt and K.W. Klinger. 1993. Multiplex PCR amplification from the CFTR gene using DNA prepared from buccal brushes/swabs. Hum. Mol. Genet. 2:159-163.

7.Roemer, S., V. Boveia, P. Humphrey, J. Amen and H. Osterman. 1997. Simultaneous bidirectional sequencing. Microb. Comp. Genomics 2:206.

8.Sarkar, G., H. Yoon and S.S. Sommer. 1992. Dideoxy fingerprinting (ddF): a rapid and efficient screen for the presence of mutations. Genomics 13:441-443.

9.Thomas, A.W., R. Morgan, M. Sweeney, A. Rees and J. Alcolado. 1994. The detection of mitochondrial DNA mutations using single stranded conformation polymorphism (SSCP) analysis and heteroduplex analysis. Hum. Genet. 94:621-623.

10.White, M.B., M. Carvalho, D. Derse, S.J.
O'Brien and M. Dean. 1992. Detecting single base substitutions as heteroduplex polymorphisms. Genomics 12:301-306.

Received 17 May 1999; accepted 27 July 1999.

Address correspondence to:

John G. Compton

Genetic Studies Section, NIAMS, NIH

6 Center Drive - MSC 2757

Bethesda, MD 20892-2757, USA

Internet: jcomp@helix.nih.gov 